\title{
DIMENSÃO ESTÉTICA, LINGUAGEM E COMUNICAÇÃO NA EXPERIÊNCIA EDUCATIVA: DIVERGÊNCIAS ENTRE DEWEY E ADORNO
}

\author{
Pedro Angelo Pagni*
}

\begin{abstract}
RESUMO
Neste artigo, analisamos as divergências entre o pensamento de Adorno e de Dewey em relação à dimensão estética da experiência educativa, a linguagem que a compreende e a comunicação que a pressupõe. No debate filosófico e educacional atual, a associação da racionalidade instrumental ao pragmatismo vem sendo contestada, com o intuito de retomar o pensamento de filósofos norte-americanos, como Dewey, para abordar temas relativos à pragmática da linguagem e à ação comunicativa. Contra essa tendência, pondera-se que também o pensamento de Adorno deveria ser retomado para pensar sobre esses problemas atuais que envolvem a experiência educativa. Desse modo, com Adorno, pensamos sobre o problema relativo aos limites da pragmática da linguagem e da ação comunicativa, postulando a importância de seu pensamento, tanto quanto o de Dewey, para enfrentar os desafios que emergem da experiência educativa na atualidade.
\end{abstract}

PALAVRAS-CHAVE: Experiência educativa. Educação e linguagem. Filosofia contemporânea.

\begin{abstract}
In this article, we analyze the differences between Dewey's and Adorno's thoughts concerning the aesthetic dimension of the educative experience as well as the language that comprises it and the communication that

* Doutor em Educação pela Universidade Estadual Paulista - UNESP (Marília - SP)
e Professor de Filosofia da Educação no curso de Pedagogia e no Programa de Pós-
graduação em Educação da Faculdade de Filosofia e Ciências da UNESP (Marília -
SP). E-mail: pagni@flash.tv.br
\end{abstract}

Educ. e Filos. Uberlândia, v. 23, n. 46, p. 169-188, jul./dez. 2009. 
presupposes it. In the current educational and philosophical debate, the association between instrumental rationality and pragmatism has been contested, aiming to resume the thought of north-American philosophers, like Dewey, in order to deal with issues related to the pragmatics of language and to communicative action. Against this trend, it is considered that also Adorno's thought should be resumed to think about these current problems which involve the educative experience. Thus, together with Adorno, we think about the problem related to the limits of the pragmatics of language and communicative action, postulating the importance of his thought, as much as Dewey's, to face the challenges which emerge from the educative experience nowadays.

KEYWORDS: Educative experience. Education and language. Contemporary philosophy.

É bastante conhecida a crítica de Adorno \& Horkheimer (1986) à racionalidade instrumental, assim como a reformulação que ela sofre na teoria da ação comunicativa, elaborada por Habermas (1987, p. 465-508). Embora admita que a racionalidade instrumental encontre-se na gênese da modernidade e do pensamento identificante, Adorno (1969) considera que ela foi expressa, em termos filosóficos, pelo positivismo lógico. Em outra ocasião, Adorno (1995b, p. 203-5) afirma que, além do positivismo lógico, a expressão contemporânea da racionalidade instrumental estaria associada ao pragmatismo. Com isso, ele parece seguir as críticas contundentes ao pragmatismo, desenvolvidas por Horkheimer (1976), no livro Eclipse da Razão. As referências de Adorno (1995a) ao pragmatismo são mais explícitas, ainda quando expande seu pensamento para compreender as questões educacionais, se referindo ao modo como essa corrente filosófica havia se entranhado na educação norte-americana e promovido a sua restrição à mera adaptação do indivíduo ao meio social existente, o que caracterizaria abandono do pensamento crítico sobre a experiência educativa.

Ao contrário desses representantes da primeira geração da Escola de Frankfurt, Habermas (1987, p. 169-91), considerou os pragmatismos de Pierce e de Dewey importantes para a formulação de uma sociologia compreensiva, à medida que envolve uma pragmática da linguagem e uma 
teoria da comunicação que poderiam ser recuperadas criticamente para a elaboração de uma teoria da ação comunicativa, nos termos que ele veio a desenvolver.

A associação do pragmatismo à racionalidade instrumental, elaborada pelos frankfurtianos da primeira geração, propagada e modificada por Habermas, segundo Garrison (1999), acabaram por distorcer o instrumentalismo filosófico elaborado por Dewey, afastando muitos leitores da interpretação de sua obra e da importância que assume para o debate filosófico contemporâneo e para a filosofia da educação. Afinal, para ele, o instrumentalismo filosófico de Dewey seria muito diferente daquilo que os frankfurtianos denominaram de razão instrumental, estando tal designação muito mais associada aos propósitos do positivismo lógico do que do pragmatismo. Nesse sentido, o autor procura reinterpretar o instrumentalismo filosófico de Dewey e, sobretudo, rebater as críticas de que ele estaria: restrito ao mero ajustamento de meios a fins dados compreenderia apenas os aspectos racionais e lógicos da experiência do agente com o mundo ou se caracterizaria somente como um ato cognitivo do pensamento, pautado num certo subjetivismo. Para ele, o erro dessas críticas estaria em associar o experimentalismo de Dewey àquele esboçado por Hume e não à filosofia aristotélica. Contra essas críticas e esse erro, o autor elucida no pensamento deweyano: o instrumentalismo como algo mais amplo e dinâmico do que a operação lógica de ajustamento meiosfins, a qualidade estética da noção de experiência em que se assentam as emoções e os desejos que a envolvem, assim como a sua concorrência para as deliberações do pensamento, contrapondo-se a essa atribuição de subjetivismo e assumindo que Dewey teria uma posição "realista transacional". Desse modo, Garrison procura relativizar as críticas que recaíram sobre o pensamento deweyano e atualizá-lo para, com ele, analisar os problemas filosóficos e educacionais contemporâneos.

Tanto a interpretação de Habermas quanto a de Garrison, assim, parecem concorrer para relativizar a associação do pragmatismo à racionalidade instrumental e, consequentemente, amenizar a crítica da primeira geração da Escola de Frankfurt a essa corrente do pensamento norte-americano. Embora se reconheça que a relativização empreendida por eles seja de suma importância para recuperar criticamente a pragmática 
da linguagem, e reatualizar o instrumentalismo filosófico de Dewey, não se pode perder de vista as divergências suscitadas por Horkheimer e, principalmente, Adorno em relação ao pragmatismo e, até mesmo, aos temas dele recuperado na atualidade. São essas divergências que pretendemos analisar neste artigo, reconstituindo os argumentos de Dewey e de Adorno sobre a qualidade ou a dimensão estética da experiência educativa, assim como o modo como compreendem os limites e as possibilidades do significado atribuído a essa experiência pela linguagem e de sua comunicação na sociedade. A partir da elucidação dessas divergências, postulamos que o pensamento de Adorno, tanto quanto o de Dewey, deva ser recuperado na atualidade enquanto uma das perspectivas em jogo no debate filosófico contemporâneo.

\section{Experiência como arte e a qualidade estética da educação na perspectiva deweyana}

A filosofia, para Dewey (1979, p. 356-9), é uma atitude que pretende compreender as particularidades do mundo de modo "coerente" e do modo "mais completo possível", dando unidade a elas, a fim de influenciar o procedimento e a direção da vida. É essa atitude da filosofia em relação à vida que a diferencia da ciência, muito mais preocupada em conhecer objetivamente os fatos particulares. Certamente que as descobertas científicas influenciaram na conduta humana, pois, sugeririam coisas a fazer e meios de execução, mas quando a ciência deixa de ser um "catálogo de fatos particulares descobertos" e passa a ser uma "atitude geral" para com o mundo e para com a vida, ela torna-se filosofia. Nesse sentido, a ideia de totalidade na qual se pautou a filosofia até então, deveria ser revista, não significando mais "a tarefa impossível de uma acumulação quantitativa", mas uma "coerência de um modo de reagir em face da pluralidade das coisas que acontecem". Isso não significaria admitir uma "identidade completa" com o mundo, já que a mesma coisa não acontece duas vezes nem são percebidas do mesmo modo, mas assumir uma identidade possível que deveria ter continuidade com a reação anterior. Afinal, para ele, a totalidade significa: 
[...] continuidade - o prosseguimento de um primeiro hábito de agir com a readaptação necessária para conservá-lo vivo e em evolução. Ao revés de significar um completo plano de ação apriorístico, significa a manutenção do equilíbrio em uma multidão de atos diversos, de modo que cada um tome a significação de outro ato e dê também significação a outro. Toda a pessoa de espírito franqueado e sensível a novas percepções e que profunda e responsavelmente lhes percebe as relações entre si, terá, na proporção em que o fizer, atitude filosófica. (DEWEY, 1979, p. 358)

Essa atitude filosófica seria compreendida como a "faculdade de aprender, de extrair significação até das desagradáveis vicissitudes da vida e transformar aquilo que foi aprendido em aptidão para continuar a aprender". Tal atitude não teria outro fim senão o de atingir "níveis mais profundos de significação" - contrariando a pretensão da filosofia ou da metafísica em estabelecer fins últimos e causas definitivas para o pensamento e a ação humanos. Além disso, ela envolveria um ato de pensar distinto do conhecimento, pois este seria relativo mais à ciência, enquanto que aquele se aplicaria às "coisas em perspectiva", sendo gerado por uma "incerteza" e visando "dissipar uma perturbação". Dessa forma, conforme Dewey $(1979$, p. 359)

Filosofia é pensar o que aquilo que é conhecido requer de nossa parte - qual atitude de correspondência que ela exige. É uma idéia do que é possível, e não um registro de fatos consumados. Por essa razão é hipotética, assim como todo ato de pensar. [...] Pode-se quase definir a filosofia como o pensamento que se tornou consciente de si mesmo que generalizou seu lugar, função e valor na experiência.

Dewey concebe a experiência como algo contingente, não teleológico, que faz com que o homem adquira por seu intermédio um maior controle e previsibilidade em suas ações, sem que isso implique, necessariamente, em chegar a uma verdade definitiva sobre ela. Embora propicie uma sensação de integralidade quando concluída, isto é, quando chega ao término de determinados fins, deliberados conscientemente pelo 
agente que a desenvolve, já que envolve toda a vida e consiste na própria vida, a experiência é um processo contínuo, humano, em que o homem reflete sobre ela e a reconstrói, modificando-se a si mesmo ao mesmo tempo em que modifica o meio em que aquela ocorre. Ela, assim, sempre é limitada enquanto objeto do conhecimento e do pensamento humanos e, concomitantemente, limita as condições destes últimos se desenvolverem em função das múltiplas formas que a experiência assume que se enredam na e é a própria dinâmica da vida.

Em virtude dessa infinitude de experiências e dos limites do conhecimento e do pensamento humanos, Dewey reconhece não ser possível chegar a uma verdade única a respeito do mundo nem a uma razão absoluta, nem a um sujeito cognoscente universal capaz de compreender a totalidade das coisas racionalmente e o ser no mundo em todas as suas determinações. Para Dewey (1959), existiria apenas a possibilidade da experimentação através do pensamento reflexivo e da teoria da investigação ou do inquérito, que tornariam a experiência humana determinada segundo deliberações conscientes, conferindo a ela um sentido, sempre provisório, sujeito a prova e dependente das condições contextuais aonde se desenvolve. Essa experimentação não se prestaria propriamente à universalização de um pensamento ou dos resultados dessa lógica ou teoria da investigação, mas no máximo, promoveria generalizações hipotéticas para o referido contexto, a serem comprovadas e consentidas, graças à intercambialidade $\mathrm{e}$ a comunicação dessas experiências, por meio da linguagem e das condições de possibilidade de seu uso nesse ou em outros contextos linguísticos. Contudo, tal potencialidade de generalização sob tais condições estaria sujeita, segundo Dewey (1959b), a uma dinâmica constante e, com isso, à própria possibilidade de reconstrução do pensamento e dos resultados do inquérito, trazendo em si mesma os germes da mudança que, por tratar-se da linguagem e de seu uso público, por assim dizer, teria um caráter eminentemente social. Nesse sentido, a experiência dependeria do pensamento reflexivo e, por sua vez, este dependeria daquela, para se modificarem mutuamente e acompanharem a dinâmica social da vida.

Ora, foi essa dupla mudança - a do agente e a do meio onde atua, por intermédio da experiência - pensada pelo instrumentalismo filosófico deweyano que fez com que Garrison (1999) denominasse essa filosofia 
de "realista transacional", que em tese, relativizaria a associação dessa filosofia à racionalidade instrumental. Partindo da dúvida suscitada quando os hábitos de ação fossem interrompidos ou quando as suas crenças fossem abaladas, o agente se empenharia em compreendê-la e significá-la, através do ato de pensar reflexivo, formulando hipóteses a serem verificadas e certificadas na mesma experiência com a realidade da qual se origina. Isso implicaria no aprimoramento dos hábitos de pensar e de agir vigentes, consistindo em sua reconstrução, assim como a das crenças construídas socialmente, no sentido de reformulá-las e compartilhá-las no ambiente comunicacional e linguístico do qual decorreram. Nesse processo de reconstrução e de redirecionamento racional da experiência estariam contidos não apenas a adaptação biológica dos agentes ao existente, como também o aprimoramento do comportamento racional daqueles frente a este e a conseqüente possibilidade de mudança do agente, através da construção de novas formas de agir e de pensar, que se opõe às habituais, definidas nesse contexto comunicacional. Estariam investidos nesse processo de atribuição de significados a essa experiência vivida e de sentido racional à vida, por intermédio do pensamento reflexivo e da teoria da investigação, em que a linguagem é o instrumento dos instrumentos, também uma dimensão sensível, emocional e estética. E seria justamente esta dimensão que permitiria a integralidade da experiência intelectual com o pensamento, quando não a desencadearia.

De fato, quando lemos o artigo "A experiência como arte" de Dewey (1980) é possível notar o sentido artístico que atribui à experiência do agente com o mundo e, consequentemente, o quanto tal sentido está a serviço da criação ao invés da mera adaptação. Por intermédio da reconstrução do pensamento reflexivo que ordena racionalmente o significado dessa experiência com o mundo, o agente a compreende no contexto em que se desenvolve. Mas, para tanto, a elaboração desse pensamento depende do empenho não apenas dos hábitos cognitivos e da lógica utilizada enquanto um recurso, como também do comportamento emocional e desejante envolvido nessa mesma experiência e mundo. Nesse sentido, essa experiência com o mundo almejaria não apenas a socialização do agente, como também uma outra possibilidade ordenação racional, construída e criada hipoteticamente e testada, por ele, no contexto de comunicação em que é gerada.

Educ. e Filos. Uberlândia, v. 23, n. 46, p. 169-188, jul./dez. 2009. 
Essa possibilidade de ordenação racional do mundo pelo pensamento possui o sentido de suscitar mudança de valores em relação àqueles estabelecidos nessa comunidade ou de acomodar-se a eles, dependendo da deliberação a ser ponderada e da disposição volitiva do agente. Somente assim, segundo ele, o agente poderia conferir unidade a uma experiência e a experienciar integralmente pelo pensamento, inclusive em suas qualidades estéticas, chegando a uma conclusão plausível num dado contexto e consumando um movimento do pensar sobre o mundo empírico que o afeta e que é afetado por ele.

Portanto, uma experiência de pensamento tem sua qualidade estética própria. Difere daquelas experiências que são reconhecidas como estéticas, mas somente com respeito a seus materiais. [...] É uma das razões pelas quais a arte estritamente intelectual nunca será popular como é a música. Contudo, a própria experiência tem uma qualidade emocional satisfatória, porque possui uma integração interna e uma realização alcançada por um movimento ordenado e organizado. Tal estrutura artística pode ser imediatamente sentida. Sob este aspecto, é estética. [...] O que é ainda mais importante é que não apenas é essa qualidade um motivo significativo para empreender uma investigação intelectual e para que seja conduzida honestamente, como também nenhuma atividade intelectual será um acontecimento integral (uma experiência), a menos que seja integralizada pela mencionada atividade. Sem ela, o pensar é inconclusivo. Em suma, o estético não pode ser separado de modo taxativo da experiência intelectual, já que esta deverá apresentar cunho estético a fim de que seja completa. (DEWEY, 1980, p. 91)

A essa experiência intelectual deveriam se integrar os sentimentos e as emoções e os desejos de que padecemos e de que nos comprazemos, assim como ser integrados por eles, num sentido semelhante à criação artística e à recepção da obra de arte: não nos reconhecendo no objeto dado e apresentado aos nossos sentidos e sim os recebendo ativa e criativamente, transformando-os, a fim de vivenciar uma sensação de integralidade. Essa recepção ativa e sensação propiciada pela qualidade estética da experiência, porém não estaria restrita somente à vida individual, como também envolveria 
a vida comunitária, já que esta determinaria os instrumentos linguísticos que seriam utilizados, assim como os valores morais e estéticos acordados nessa comunidade, permitindo que o seu agente deliberasse sobre a sua concordância ou discordância sobre eles e se empenhasse em conservá-los ou modificá-los. Mais do que isso, pensar reflexivamente essa experiência envolveria reconhecer, inclusive, as diferenças de opinião que tal reflexão geraria na comunidade a qual se destina, conforme os interesses envolvidos.

Essas diferenças acerca da percepção das causas de qualquer perturbação ocorreriam em função dos interesses dos grupos e dos conflitos existentes entre eles numa mesma comunidade. Esses grupos teriam experiências diferentes entre si, atribuindo significados distintos às causas de suas crises comuns ou, por assim dizer, referentes à comunidade em que vivem. Esta é a razão da existência de "filosofias rivais" e destas, cada uma a seu modo, procurarem propor uma solução para a crise ou conflito de interesses em que vivem, em geral, propondo um "programa de adaptação social”.

Para Dewey (1979, p. 361), esse é o ponto de "íntima relação" entre a filosofia e a educação. O estabelecimento de um "programa de adaptação social" não seria diferente para o pragmatismo, caso quisesse influenciar as pessoas a adotarem a sua "teoria" de modo não artificial, devendo para tanto realizá-lo pela educação, já que ela "oferece um terreno vantajoso para se penetrar na significação humana (para diferenciar-se da significação técnica) das discussões filosóficas". Isso porque a educação poderia habilitar-nos a encarar os problemas filosóficos no terreno em que eles surgem e lutam - local onde sua aceitação ou rejeição resultaria numa diferença prática. Se a educação for considerada, diz ele, como um "processo de formação de atitudes fundamentais, de natureza intelectual e sentimental, perante a natureza e os outros homens, pode-se até definir a filosofia como uma teoria geral da educação". Dewey concebe, assim, a sua filosofia como uma filosofia da educação por excelência.

Essa filosofia deveria compreender, segundo ele, a natureza da experiência que estaria na base de todo fenômeno ou atividade educativa. Para Teixeira (1980, p. 116-18, grifos no original), Dewey teria definido a educação "como o processo de reconstrução e reorganização da experiência, pelo qual the percebemos mais agudamente o sentido, e com isso nos 
habilitamos a melhor dirigir o curso de nossas experiências futuras". Seria por intermédio desse esse processo de reconstrução e reorganização da experiência que o indivíduo garantiria a continuidade da vida individual, adaptando-se às novas situações exigidas socialmente, como também a perpetuação da própria vida social, já que esta depende da reformulação das crenças, dos costumes e dos desejos para continuar se aprimorando.

A experiência educativa envolve, por assim dizer, uma qualidade não apenas racional, como também estética. Ela pode ser considerada como uma arte que envolve a reorganização e reformulação das experiências passadas diante dos problemas presentes e das possibilidades de projeção para enfrentar o futuro, referindo-se à vida do indivíduo, às suas vivências, como também à história da humanidade e à vida social. No fundo, o processo educativo seria um dos meios de garantir a integralidade da experiência para os indivíduos, envolvendo suas disposições emocionais e racionais, e para a comunidade que compartilham as experiências singulares, compreendendo racionalmente os interesses em jogo e os consensos relativos às leis, às crenças, aos costumes e aos desejos, que garantiriam o bom funcionamento social. À comunicação destes últimos caberia garantir a continuidade entre passado e futuro, através da formação das novas gerações e, ao mesmo tempo, da remodelação dos velhos hábitos de pensar e de agir, propiciando uma dinâmica das relações sociais que não se restringiria apenas a manutenção de um único funcionamento social.

Além das próprias relações sociais que a promovem, os educadores seriam responsáveis por promover essa comunicação flexível e aberta, funcionando como uma espécie de emissores das mensagens compartilhadas pela comunidade, na qual interage com os significados que a congregam e o sentido empregado em sua conduta perante a vida. Para promover a comunicação dessas mensagens, das experiências e dos significados sociais que congregam linguisticamente falando, além da atitude geral do educador perante a vida, seria necessário um receptor, no caso do processo educativo estrito senso: o aluno. Similarmente a qualidade estética da experiência, ao invés de se reconhecer naquela mensagem, experiências compartilhadas e significados, esse aluno as receberia ativamente, modificando-as ou se adaptando a elas conforme os seus interesses e as demandas do contexto em que vivem. Julgados através de uma deliberação consciente e decididos pela 
assunção de uma atitude por parte do aluno, essa emissão do educador pode ou não suscitar naquele uma experiência conclusiva e integral sobre as suas consequências no mundo existente, assim como uma relação destas com os seus desejos e perspectivas futuras que se delineiam pela auto-reflexão constante sobre esse seu estar nesse mesmo mundo. Essa experiência educativa do aluno, suscitada pelo educador, estaria condicionada não apenas aos recursos e meios utilizados por ele para tal empreendimento, como também os interesses e os desejos indispensáveis para promovê-la integralmente e para o desenvolvimento do pensar reflexivo sobre aquilo que vivem no presente. Dependeria para tanto de uma pedagogia que a contemplasse e seguisse os passos necessários para o desenvolvimento do pensar reflexivo, a começar pela interrupção dos hábitos de ação e de pensamento dos alunos, através da organização, pelo educador, dos meios em que se desenvolve essa experiência educativa.

De acordo com Dewey (1979, p. 87-106), essa experiência educativa poderia ser propiciada pela escola, desde que essa instituição fosse regida por princípios democráticos e existisse numa sociedade democrática, isto é, uma sociedade constituída por grupos sociais cujos interesses fossem compartilhados por todos os seus membros e que não impedissem o pleno e livre intercâmbio de experiências - a comunicação entre eles. Para tanto, a comunidade com a qual se relacionaria essa instituição e a sociedade na qual existe deveria ser regida por esses princípios e por certa abertura, não apenas para socializar as novas gerações, como também para aprender com esses agentes e com o conflito decorrente da mudança desses valores, estabelecido a cada geração. A democracia seria, assim, a condição para que a educação promovesse o aprimoramento da vida social e humana, sem cercear o compartilhamento e o livre intercâmbio dos significados atribuídos às experiências e a reconstrução destes na comunidade lingüística aos quais se destinam, conforme seus propósitos futuros e suas disposições atuais, gerados pelos múltiplos interesses e pela pluralidade de posições em jogo nessa sociedade. Tolerar essa pluralidade e, ao mesmo tempo, forjar um sentido e uma confluência de interesses comuns a essa diversidade de experiências existentes seria o pressuposto para que ocorresse a comunicação necessária à democracia e à educação. 


\section{A inaptidão à experiência e a dimensão estética da experiência educativa}

Se Dewey concebe a experiência humana como uma continuidade entre a natureza e a cultura, significada pela linguagem e desenvolvida em determinados contextos comunicacionais, os frankfurtianos a analisam, reconhecendo os seus limites num contexto em que a natureza recalcada pela civilização mostrou as suas garras e a cultura converteu-se em semicultura socializada nas sociedades industriais avançadas, tornando o seu significado difícil de aprender e de comunicar pelas palavras, impedindo pensá-la através do conceito.

O diagnóstico de Benjamin (1986) sobre o empobrecimento da experiência humana após a Primeira Guerra Mundial, a ponto dos soldados voltarem silenciosos sem nenhuma história a narrar ante as atrocidades vividas, parece ser radicalizado por Adorno. Após a Segunda Guerra, segundo Adorno, não apenas os soldados não teriam mais nenhuma experiência a relatar nem se empenhariam em significar ou conceitualizar as atrocidades cometidas, como também as vítimas das perseguições e aqueles que fecharam os olhos às crueldades impetradas pelo nazismo fizeram questão de esquecêlas e de se silenciar historicamente sobre esse supremo mal que se abateu sobre a humanidade. Tal incapacidade de rememorar esse passado recente, de colocá-lo à mostra e, com isso, reabrir essa ferida teria sido responsável por uma destruição da memória, desenvolvida em nome da razão subjetiva e de uma racionalidade instrumental, para a qual a educação teria concorrido ao não se empenhar na tarefa de elaboração do passado.

Com a proliferação da indústria cultural e com a acentuação da semiformação, após a Segunda Guerra, o mundo viu-se premido por uma racionalidade que administraria tudo, inclusive as instâncias da vida privada, subsumindo-a a mera adaptação à totalidade social estabelecida $\mathrm{e}$ às formas de totalitarismo que esta representa. Nesse contexto, a educação teria assumido a função de adaptar o aluno (e os professores) ao existente, propiciando-lhe uma experiência educativa em que a sua significação ou conceituação se desenvolveriam em torno dos significados, conceitos e valores dados pela comunidade ou sociedade existentes, restritos, portanto ao lingüístico e socialmente determinado, justificando tal concepção teoricamente pelo pragmatismo. Ou então, partindo de um existente pré-

Educ. e Filos. Uberlândia, v. 23, n. 46, p. 169-188, jul./dez. 2009. 
estabelecido, o discurso sobre a educação abandonou a emancipação enquanto tarefa da atividade educativa, justificando esse abandono por uma certa ontologia (ADORNO, 1995a, p. 169-85).

$\mathrm{O}$ antídoto que Adorno elabora contra essa inaptidão da experiência, diferentemente daquele esboçado por Dewey, é recuperar o sentido subjetivo, sensível e profundo desta última, como forma de resistir ao esquecimento do passado, à deterioração da cultura, à racionalidade instrumental e ao pensamento identificante, por intermédio de uma reeducação que seria, em si mesma, política. Diante da dificuldade em elaborar o passado e comunicar a experiência das atrocidades cometidas contra a humanidade, segundo ele, de nada adiantaria insistir no uso de argumentos que retratassem as mortes dos judeus em números ou que envolvessem a racionalidade subjetiva dos indivíduos. Mas, quem sabe, para alguns poucos indivíduos, ainda não completamente reificados, nem em constante defesa, poder-se-ia suscitar a lembrança dos bombardeios sobre as suas cidades, o barulho das bombas e dos aviões, enfim, desse outro sensível e profundo que, em si mesmo, resiste à completa significação e conceituação do horror e do medo (ADORNO, 1995a, p. 29-50).

Para tanto, não apenas esse outro deveria ser suscitado nos alunos, no sentido de recobrarem essa experiência e falarem sobre ela, com todos os limites que isso implica, como também caberia uma reeducação dos próprios educadores. A partir de uma reflexão crítica sobre a sua própria experiência formativa os professores poderiam munir-se de saberes relativos à psicologia profunda dos indivíduos e a uma sociologia que retratasse a história do tempo presente, encontrando recursos práticos e teóricos para afetar a sensibilidade daqueles aprendizes que, ainda, não se colocaram numa posição defensiva, justificatória, desresponsabilizando-se daquilo que ocorre com os outros. Se isso não concorresse para a transformação radical das condições objetivas que promovem a inaptidão à experiência, ao menos poderia engendrar uma outra atitude por parte dos professores e dos alunos, assim como poderia suscitar escolhas conscientes, como aquelas relativas às preferências pela democracia do que por qualquer forma de totalitarismo. Isso implicaria em assumir, segundo Adorno, não uma postura de pensar a experiência educativa como uma mera adaptação ao existente e sim numa atitude de resistência a este último e, sobretudo, em 
relação à tendência à barbárie que persiste na democracia, porque tributária de traços de autoritarismo que se sedimentam na psicologia profunda, não completamente controlável. Esta seria uma das formas de assumir essa atitude, elaborando o passado no presente vivenciado e evitando que este retornasse em suas formas arcaicas e violentas.

Almejando aquilo que se sedimenta na experiência profunda, praticamente ignorada por Dewey, o pensamento adorniano deseja trazêla à auto-reflexão crítica sobre si mesma e levar os agentes envolvidos na experiência educativa, a reconhecer os seus próprios limites da atividade pedagógica e, ao mesmo tempo, buscar as brechas para, estrategicamente, evitar a repetição da barbárie: a única tarefa ética e política possível para a educação, no presente. Desta perspectiva ética e política, ele propõe algumas estratégias possíveis para promover uma educação, conforme tais propósitos. Uma delas, segundo Adorno (1995 a, p. 119-38), seria promover essa forma de educação já na primeira infância: momento da vida em que os mecanismos de defesas ainda não estão completamente instaurados e a reificação da consciência ainda não se processou por completo, ficando mais fácil combatê-las.

Referindo-se à experiência infantil do aluno, ele insiste no fato de que a psicologia profunda, a psicanálise, constituir-se-ia num recurso válido para desvendá-la, reconhecendo aí o mundo sensível e pulsional que permitiria não penas promover a sensibilização desejada por meio da educação, como também o desejo de saber necessário para a relação viva com a cultura e à formação do pensar autônomo. Além disso, por intermédio dessa aproximação com a experiência infantil, o professor se aproximaria das formas da imaginação que, nesse momento, prefiguram o pensamento e, consequentemente, de uma lógica diversa daquela instaurada no mundo adulto, aprendendo com uma tensão entre a sua experiência com o pensamento e uma outra que, senão promove a significação e a conceituação da experiência sensível, ao menos indica um potencial de criação, promovido por uma curiosidade suscitada pela relação da criança com o mundo em que vive, ainda não completamente tomado pela sua completa renúncia, podendo aí se verificar a gestação de um pensamento que não renuncia a sensibilidade e a imaginação, mas, por intermédio destas, promovem aquele e com ele se comprazem. Para penetrar nesse universo

Educ. e Filos. Uberlândia, v. 23, n. 46, p. 169-188, jul./dez. 2009. 
o professor precisa reconhecer a sua própria experiência com a infância e, distanciado desta, aproximar-se de uma outra experiência que não é mais a sua e envolve um outro tempo e outros problemas, que necessita conhecer, até para diferenciar-se dela e do caos que a compreende. Nesse processo dialético de aproximação e de distanciamento com essa outra experiência de infância é que o professor pode adentrar ao mundo infantil no sentido de oferecer pistas aos seus alunos, ajudando aqueles que estiverem dispostos a ordenar racionalmente o caos em que está imersa a sua experiência com o mundo, sem abandonar a sensibilidade e a imaginação que envolve o seu pensar e o medo mundano suscitado por esse pensamento, assumindo-o como parte de seu comprazimento e de sua natureza sensível.

É nesse sentido que Adorno (1995a, p. 128-29) postula que a educação deveria aprender com a filosofia aquilo que há muito esta última já conhece, a saber: que o medo não deveria ser reprimido, mas, sim, assumido e expresso no e pelo processo de pensar. Isso significaria que o educador deveria tentar compreender a experiência trágica que ele e o seu aluno travam com o mundo (interno e externo) e pensar a experiência sensível de que a relação pedagógica é portadora. Nessa relação, também, o educando aprenderia um pensamento diferente do seu, capaz de engendrar uma outra atitude reflexiva e um pensamento autônomo sobre o mundo existente, assumindo as conseqüências de seu pensar e de seu agir. A experiência educativa do aluno não se processaria, assim, apenas por meio da identificação dos conceitos produzidos pelo pensamento com o mundo no qual vivem, com o intuito de promover uma adaptação daquele ao existente, como também, pelo reconhecimento da complexidade da realidade e a dinâmica que compreende o pensá-la, almejando a geração de uma tensão produtiva no embate comunicacional e resistência ao existente.

Ciente dos limites para que a realidade seja apreendida racionalmente em sua totalidade e tentando evitar que essa dinâmica do pensar se restrinja ao pensamento identificante, justificado pela autoconservação da espécie ou de sua evolução diante as mudanças ambientais, na concepção adorniana, essa experiência consistiria no não esgotamento do pensar sobre o presente e no presente, mas numa constante abertura ao mundo por parte desse pensar, tentando elucidar os segredos que habitam aquele e os (des)caminhos deste, dificilmente expressos linguística e conceitualmente, por tratar-se 
de uma natureza subjetiva profunda, distinta daquela objetivamente dada. Nesse sentido, essa experiência educativa, que envolve a comunicação e o compartilhamento de outras experiências com o saber e com o pensar, por parte de seus agentes, encontrar-se-ia limitada àqueles propósitos, a menos se admitíssemos as formas de violência e de poder que a envolvem, numa sociedade como a nossa, sendo este um dos modos de enfrentarmos essa situação.

Isso porque as formas de violência e de poder que envolve essa comunicação, e toda aquela estabelecida socialmente, só seria emancipada através da emancipação da própria sociedade que a engendra e que é regida pelo princípio de dominação. Como as condições para essa emancipação encontram-se fora de questão, no mundo totalmente administrado, restaria apenas à comunicação que envolve a experiência educativa esforçar-se por expressar o não idêntico e por denunciar toda a violência, real ou simbólica, que se exerce na situação atual, considerando-se também como uma forma de poder que tenta miná-las, juntamente com tantas outras, resistindo às formas de pensar, aos hábitos, aos costumes e as crenças estabelecidos sob o princípio da identificação e da dominação.

Se Dewey pensa a democracia como uma situação onde a comunicação e o compartilhamento das experiências poderiam ocorrer sem a violência real e simbólica, a ser construído historicamente, através do uso comum da linguagem e de seu emprego para definir os valores, as normas e as crenças consensuais, Adorno parece admitir uma pluralidade de perspectivas estabelecidas nesse contexto comunicativo, porém, em confronto umas com as outras. O frankfurtiano assume com isso a perspectiva dos não completamente integrados na totalidade social e na linguagem comum ou, ao menos, daqueles que resistem a tal integração. É dessa perspectiva, em termos linguísticos, que ele parece: interrogar estas últimas; problematizar a integração da consciência dos indivíduos à totalidade social e a pragmática da linguagem comum que se constitui em torno do estabelecido ou de consensos relativos a conceitos e valores; postular a individualidade a ser constituída por uma experiência autoeducativa e uma filosofia que a todo instante busca o outro da linguagem ou o seu sentido eminentemente privado que não se pode comunicar ou compartilhar-por reconhecer-se no esforço de comunicar o incomunicável 
- e que, por assim dizer, promoveria intencionalmente o dissenso ao invés da unanimidade consensual. Tanto na sua própria concepção de experiência educativa quanto na comunicação que a envolve o pensamento adorniano estaria, desse modo, bastante distante do pragmatismo e, sobretudo, do positivismo lógico, assim como, acrescento eu, de algumas correntes da filosofia analítica - até porque, neste último caso, em função do pouco contato com elas -, seguindo um caminho distinto dessas filosofias e das concepções de educação que engendraram.

\section{Considerações Finais}

Mesmo relativizando a associação da racionalidade instrumental ao pragmatismo, as divergências entre este e o pensamento crítico de Adorno se perpetuam no que diz respeito à dimensão estética da experiência educativa, à pragmática da linguagem e à forma como compreendem a comunicação, propondo uma outra prática educativa que não apenas consista em se adaptar ao existente para reconstruí-lo e, sim, em resistir a ele e buscar na experiência subjetiva profunda aquilo que promove a dominação e limita a comunicação livre de violência. Se Dewey vem sendo retomado no debate filosófico e educacional contemporâneo, por aquilo que o seu pensamento concorre para a pragmática da linguagem e para a ação comunicativa e para o desenvolvimento de uma qualidade estética da experiência educativa, pode-se dizer que também poderíamos pensar com Adorno esses problemas atuais, porém, emprestando a eles um outro sentido.

É o que parece fazer Lyotard (1996) nesse debate, quando interroga essa pragmática e essa ação comunicativa, contrapondo-se as posições assumidas por Habermas e por Rorty, por exemplo, recorrendo não apenas ao pensamento crítico adorniano e à sua teoria estética, como também à noção wittegensteiniana de jogos de linguagem para postular a comunicação do diferenciado na experiência com o pensamento e o caráter produtivo do dissenso, antes que do consenso, na ação comunicativa. Contudo, mesmo essa apropriação do pensamento adorniano, desenvolvida por Lyotard, deve ser vista com certo cuidado, guardando as suas diferenças. Isso porque, como sugere Dews (1996, p. 66-7), o pensamento de Adorno

Educ. e Filos. Uberlândia, v. 23, n. 46, p. 169-188, jul./dez. 2009. 
teria insistido no trabalho auto-reflexivo sobre o sujeito, tornando-o parcialmente consciente, enquanto que Lyotard teria tentado dissolver essa noção e substituí-la pelos dispositivos da dinâmica do desejo ou das forças, sendo ela própria resultado da confluência da vontade de poder. Assim procedendo, e reconhecendo também essas outras divergências, podese compreender o pensamento adorniano naquilo que ainda o mantêm vivo, ainda que reconstruído perante um outro contexto e para uma outra filosofia. Nesse sentido, o pensamento adorniano poderia ser retomado, tanto quanto o pensamento de Dewey, com o intuito de produzir alguns paralelismos no debate filosófico e educacional atual, permitindo que pensemos com cada um deles, os problemas que, muitas vezes eles não se colocaram, como aqueles relativos à experiência educativa aqui analisados. Desse modo, nesta comunicação, procurou-se pensar com Dewey e com Adorno sobre a dimensão estética compreendida na experiência educativa, a linguagem que tenta apreendê-la e a comunicação que a envolve, elucidando as divergências suscitadas por eles em relação ao assunto e abrindo caminho para o desenvolvimento de outros estudos sobre as suas eventuais convergências.

\section{Referências}

ADORNO, T.W. Educação e Emancipação. São Paulo: Paz \& Terra, 1995a. 1969. Para qué aún la filosofia? Intervenciones. Caracas: Monte Avila,

. Sobre sujeito e objeto. Palavras e Sinais. Petrópolis: Editora Vozes, 1995b, p.181-201.

ADORNO \& HORKHEIMER, M. Dialética do Esclarecimento. 2 ed. Rio de Janeiro: Jorge Zahar Editor, 1986.

BENHABIT, S. A crítica da razão instrumental. ZIZEC, S. Um mapa da ideologia. Rio de Janeiro: Contraponto, 1996.

BENJAMIN, W. Experiência e pobreza. Documentos de Cultura, documentos de barbárie: escritos escolhidos. São Paulo: Cultrix, 1986, p. 195-99.

Educ. e Filos. Uberlândia, v. 23, n. 46, p. 169-188, jul./dez. 2009. 
DEWS, P. Adorno, pós-estruturalismo e a crítica da identidade. Zizek, S. (Org.) Um mapa da ideologia. Rio de Janeiro: Contraponto, 1996, p. 51-70.

DEWEY, J. Como pensamos: como se relaciona o pensamento reflexivo com o processo educativo. 3 ed. São Paulo: Companhia Editora Nacional, 1959.

Democracia e Educação. 4. Ed. São Paulo: Cia. Editora Nacional, 1979

A Experiência como arte. Coleção Os Pensadores: Dewey. São Paulo: Abril Cultural, 1980.

GARRISON, J. John Dewey's Theory of Practical Reasoning. Educational Philosophy and Theory. 1999.

HABERMAS, J. Teoría de la acción comunicativa. Madrid: Taurus, 1987, v. 1.

HORKHEIMER, M. Eclipse da Razão. Rio de Janeiro: Editorial Labor do Brasil, 1976.

LYOTARD, J. F. Moralidades Pós-modernas. Campinas: Papirus, 1996.

TEIXEIRA, A. A Pedagogia de Dewey. Coleção Os Pensadores: Dewey. São Paulo: Abril Cultural, 1980.

Data de registro: 06/06/08

Data de aceite: 17/10/08 
